\title{
The relationship between Agent Orange and prostate specific antigen: a comparison of a hotspot and a non-sprayed area in Vietnam
}

\author{
XianLiang Sun - Teruhiko Kido $\cdot$ Rie Okamoto $\cdot$ Ho Dung Manh $\cdot$ Nguyen Viet Hoang \\ Madoca Nakano • Eitetus Koh - Shoko Maruzeni - Muneko Nishijo - Hideaki Nakagawa • \\ Hiroyuki Suzuki $\cdot$ Sejiro Honma $\cdot$ Dang Duc Nhu $\cdot$ Nguyen Ngoc Hung $\cdot$ Le Ke Son
}

Received: 22 November 2012/Accepted: 21 January 2013/Published online: 23 March 2013

(c) The Japanese Society for Hygiene 2013

\begin{abstract}
Objectives The aim of this study was to explore the impact of Agent Orange exposure for prostate cancer with a comparison of the prostate specific antigen (PSA) levels between a hotspot and a non-sprayed area.

Methods The study was conducted in Phu Cat district (hotspot) and Kim Bang district (non-sprayed), with a total of $101 \mathrm{men}$ in the hotspot and $97 \mathrm{men}$ in the non-sprayed area older than 50 years of age. About $5 \mathrm{~mL}$ of whole blood and a health status questionnaire were collected from each subject in August 2009-2011.

Results The mean age of the subjects in the hotspot (68.0 years old) was significantly higher than that of those in the non-sprayed area (65.0 years old). No significant difference was found between the hotspot area $(0.93 \mathrm{ng} / \mathrm{mL})$ and the non-sprayed area $(0.95 \mathrm{ng} / \mathrm{mL})$ in
\end{abstract}

X. Sun $(\bowtie) \cdot$ H. D. Manh · N. V. Hoang · M. Nakano Division of Health Sciences,

Graduate School of Medical Science, Kanazawa University,

5-11-80 Kodatsuno, Kanazawa, Japan

e-mail: sunxianliangjapan@yahoo.com

T. Kido $\cdot$ R. Okamoto

Faculty of Health Sciences, Institute of Medical Pharmaceutical and Health Sciences, Kanazawa University,

5-11-80 Kodatsuno, Kanazawa, Japan

e-mail: kido@mhs.mp.kanazawa-u.ac.jp

\section{E. Koh}

Department of Urology, Faculty of Medicine,

Institute of Medical Pharmaceutical and Health Sciences,

Kanazawa University, 13-1 Tkara-machi,

Kanazawa, Japan

S. Maruzeni - M. Nishijo $\cdot$ H. Nakagawa

Department of Public Health, Kanazawa Medical University,

1-1 Daigaku, Uchinada, Ishikawa, Japan terms of PSA levels. Likewise, this was not statistically significant after adjusting for age. The prevalence of high PSA levels ( $>3 \mathrm{ng} / \mathrm{mL}$ ) did not differ significantly between the hotspot (14 men; $13.9 \%$ ) and non-sprayed area ( 9 men; $9.3 \%)$. No significant difference was found between the hotspot area and the non-sprayed area in terms of occupation (farmer and others). In control subjects, no significant difference was found between the PSA levels in subjects exposed to Agent Orange and non-exposed subjects. Likewise, no significant difference was found between the PSA levels of combatants and civilians. Conclusion The PSA levels were not significantly different between the hotspot and the non-sprayed area.

Keywords Agent Orange $\cdot$ PSA (prostate specific antigen) · Prostate cancer · Hotspot · Vietnam

\author{
H. Suzuki \\ Department of Life and Health Science, Chubu University, \\ 1200 Matusmoto, Kasuga, Aichi, Japan \\ S. Honma \\ ASKA Pharma Medical Co. Ltd, 5-36-1 Shimosakunobe, \\ Kawasaki, Japan \\ D. D. Nhu $\cdot$ N. N. Hung \\ 10-80 Division, Hanoi Medical University, \\ No. 1 Ton That Tung, Dong Da, Hanoi, Vietnam \\ L. K. Son \\ Environment Administration, Ministry of Natural Resources \\ and Environment, 67 Nguyen Du Street, Hanoi, Vietnam
}




\section{Introduction}

Between 1962 and 1971, the United States Air Force sprayed approximately 107 million pounds of herbicides in South Vietnam for the purpose of defoliation and crop destruction in a program code-named Operation Ranch Hand [1]. During the course of this operation, hundreds of thousands of United States service personnel and millions of Vietnamese were exposed to the chemicals in the air, water, and soil and through food raised on contaminated farms [2].

The herbicides sprayed during the Vietnam era contained mixtures of 2,4-dichlorophenoxyacetic acid (2,4-D), 2,4,5trichlorophenoxyacetic acid $(2,4,5-\mathrm{T})$, picloram, and cacodylic acid. The most extensively used defoliant, a 50:50 combination of 2,4-D and 2,4,5-T, has since been found to have been contaminated with between $<0.05$ and almost 50 parts per million of 2,3,7,8-tetrachlorodibenzo- $p$-dioxin (TCDD), which came to be known as "Agent Orange" [3].

In 1998, the National Academy of Science concluded that "limited/suggestive evidence" existed of an association between Agent Orange and prostate cancer [4]. Previous studies involving Vietnam veterans had accumulated evidence regarding Agent Orange exposure and the subsequent development of prostate cancer [5-8]. Concerns over the potential health effects of Agent Orange in United States and Australian veterans exposed to herbicides during the Vietnam War led to a number of studies concerning cancer mortality, including prostate cancer [7-9]. The largest study to analyze the link between Agent Orange and prostate cancer examined the medical records of more than 13000 Vietnam War veterans. Among those men who reported exposure, Agent Orange was found to greatly increase the risk of prostate cancer, particularly the risk of suffering the most aggressive form of this disease, compared to those who were not exposed [10].

In previous phases of the Air Force Health Study of Agent Orange exposure and incidence of prostate cancer in Air Force veterans involved in Operation Ranch Hand, PSA screening was used to detect prostate cancer in Vietnam veterans over the period 1999-2003 [10]. Prostate-specific antigen (PSA) is a protein that is produced by the cells of the prostate gland and enters the bloodstream. Although the highest amounts of PSA are found in semen, some PSA escapes the prostate and can be found in the serum. This serum component has been used to track the response to therapy in men with prostate cancer. Since the late 1980s, PSA has been studied clinically and is currently used to detect, stage, and monitor prostate cancer [11]. Recent studies of the relationship between Agent Orange and prostate cancer focused on American Vietnam War veterans, whereas there are few studies concerning the relationship between Agent Orange and PSA in
Vietnamese men. The aim of this study was therefore to explore the impact of Agent Orange exposure for prostate cancer with a comparison of the PSA levels between a hotspot area and a non-sprayed area.

\section{Methods and materials}

\section{Subjects}

The subjects were stratified as either living in Phu Cat or Kim Bang district. Phu Cat airbase (Binh Dinh province) is one of three main dioxin hotspots in southern Vietnam, and the study subjects were known to have been living in and around the airbase prior to the war. Kim Bang district (Ha Nam province) is located in northern Vietnam and did not experience herbicide operations during the war, which is why it was selected as the non-sprayed area. Nhu et al. [12] reported that dioxin levels in the breast milk of Vietnamese primiparas in the hotspot area were significantly higher than those in the nonsprayed area. In light of this, we hypothesized that PSA levels may also differ between the hotspot area and the non-sprayed area. Therefore our study subjects consisted of 101 men from the hotspot area and 97 men from the non-sprayed area, all of whom were selected randomly from men aged 50 years or older in these areas.

\section{Methods}

In August 2009, 2010, and 2011, 198 Vietnamese (101 Vietnamese from Phu Cat and 97 Vietnamese from Kim Bang) participated in this cross-sectional study. All subjects provided a 5-mL sample of whole blood. In 2010, a digital rectal examination and serum PSA determination were conducted by a urologist on six men who showed high PSA levels (>3 ng/mL) in 2009 in the hotspot area. Consenting subjects were required to complete a health status questionnaire to gain individual information, including age, BMI, residence history, family history of prostate cancer, occupation, smoking history, alcohol consumption, and history of chemical exposure.

Statistical analysis

Prostate specific antigen levels were subsequently expressed on a log scale. Appropriate statistical methods, including a chi square test, Welch test, student $t$ test, and analysis of covariance (ANCOVA), were performed to compare PSA levels between the two areas after adjusting for the effect of age. Statistical analyses were performed using the JMP statistical software package, version 9.0 (SAS Institute Japan). Statistical significance was set at $p \leq 0.05$. 
Ethical considerations

Prior to beginning the study, approval was obtained from the Medical Ethics Committee of Kanazawa University [approvals no.: 89 (2007) and no.: 326 (2011)], and informed consent was obtained from all the participants in written form.

\section{Results}

The personal and demographic characteristics of the participants can be found in Table 1 . The mean age of subjects in the hotspot area (68.0 years) was significantly higher than those in the non-sprayed area (65.0 years). There were no significant differences between the hotspot and non-sprayed areas in terms of alcohol habit or smoking habit. In addition, no significant difference was found in the PSA levels between the hotspot area $(0.93 \mathrm{ng} / \mathrm{mL})$ and the non-sprayed area (0.95 ng/mL). Likewise, after adjusting for age, the PSA levels did not differ significantly between the two areas (Table 2). Nine of the subjects from the non-sprayed area and 14 of those from the hotspot area had high PSA levels $(>3$ $\mathrm{ng} / \mathrm{mL})$. However, the prevalence of high PSA levels $(>3$ $\mathrm{ng} / \mathrm{mL}$ ) did not differ significantly between the two areas.

The PSA levels of six subjects who showed high PSA levels ( $>3 \mathrm{ng} / \mathrm{mL}$ ) in 2009 were found to be higher after follow-up in 2010, except for one subject in the hotspot area (Table 3). A digital rectal examination was done by a Japanese urologist to help the detection of prostate cancer in these subjects, suggesting prostate abnormalities in three of them (No. 2, 4, 6), thus the possibility of prostate cancer. Depending on occupation (farmer and others), two questions in the multiple-choice questionnaire were excluded from the final analysis. No significant differences were found between the hotspot and non-sprayed areas on comparison of farmers' PSA levels (Table 4). Likewise, no significant differences in PSA levels were found between the hotspot and non-sprayed areas for other occupations (Table 5). Of the subjects in the control group, 71 stated that they were combatants during the Vietnam War and 26 that they were civilians. A comparison of the PSA levels between these two groups showed no significant differences (Table 6). A total of 47 subjects reported exposure to Agent Orange during the Vietnam War and a further 47 reported no exposure. Three subjects who answered "unknown" were excluded from the final analysis. A comparison of the PSA levels between exposed and nonexposed subjects found no significant differences (Table 7). In our study, residence history information was not available for many of our samples, and thus was not included in this study. A positive family history is an important risk factor for prostate cancer and therefore increases PSA levels [13]. However, in both areas no one

Table 1 Demographic characteristics of participants in the hotspot and non-sprayed areas

\begin{tabular}{|c|c|c|c|c|c|c|c|}
\hline \multirow[t]{2}{*}{ Characteristics } & \multicolumn{3}{|c|}{ Hot spot area } & \multicolumn{3}{|c|}{ Non-sprayed area } & \multirow[t]{2}{*}{$p$ value } \\
\hline & $N$ & $\begin{array}{l}\text { Mean } \pm \text { SD } \\
\text { Number }\end{array}$ & $\%$ & $N$ & $\begin{array}{l}\text { Mean } \pm \text { SD } \\
\text { Number }\end{array}$ & $\%$ & \\
\hline Age (years) & 101 & $68.0 \pm 6.1(54-81)$ & & 97 & $65.0 \pm 4.8(56-79)$ & & $0.046^{1}$ \\
\hline PSA (ng/mL) & 101 & $1.38 \pm 1.43$ & & 97 & $1.35 \pm 1.41$ & & $0.872^{2}$ \\
\hline PSA (GM GSD) (ng/mL) & 101 & $0.93 \pm 2.43$ & & 97 & $0.95 \pm 2.21$ & & $0.806^{2}$ \\
\hline PSA >3 (ng/mL) & 101 & 14 & 13.9 & 97 & 9 & 9.3 & $0.314^{3}$ \\
\hline Height (cm) & 101 & $156.9 \pm 5.5$ & & 97 & $159.3 \pm 4.9$ & & $0.001^{2}$ \\
\hline Weight (kg) & 101 & $49.2 \pm 7.6$ & & 97 & $52.5 \pm 7.8$ & & $0.003^{2}$ \\
\hline BMI $\left(\mathrm{kg} / \mathrm{m}^{2}\right)$ & 101 & $20.0 \pm 2.5$ & & 97 & $20.7 \pm 2.7$ & & $0.039^{2}$ \\
\hline Alcohol habit (yes) & 101 & 46 & 45.5 & 97 & 49 & 50.5 & $0.484^{3}$ \\
\hline Smoking habit (yes) & 101 & 62 & 61.4 & 97 & 56 & 57.7 & $0.600^{3}$ \\
\hline Present job (yes) & 101 & 69 & 68.3 & 97 & 52 & 53.6 & $0.034^{3}$ \\
\hline \multicolumn{8}{|l|}{ Kind of present job } \\
\hline Multiple choice (yes) & 69 & 2 & 2.9 & 52 & 0 & 0 & \\
\hline Farmer (yes) & 67 & 52 & 77.6 & 52 & 31 & 59.6 & \\
\hline Worker (yes) & 67 & 0 & 0 & 52 & 1 & 1.9 & \\
\hline Fisher (yes) & 67 & 0 & 0 & 52 & 1 & 1.9 & \\
\hline Teacher (yes) & 67 & 0 & 0 & 52 & 0 & 0 & \\
\hline Other job (yes) & 67 & 15 & 22.4 & 52 & 18 & 34.6 & \\
\hline
\end{tabular}

$S D$ standard deviation, $G M$ geometric mean, GSD geometric standard deviation, $B M I$ body mass index

${ }^{1}$ Welch test, ${ }^{2}$ Student's $t$ test, ${ }^{3}$ chi squared test 
Table 2 Covariance analysis for age and PSA between the hotspot and non-sprayed area

\begin{tabular}{lrlrl}
\hline Term & Estimate & Std error & $t$ Ratio & Prob $>|t|$ \\
\hline Intercept & -1.060456 & 0.31217 & -3.40 & 0.0008 \\
Area & -0.018832 & 0.02573 & -0.73 & 0.4652 \\
Age & 0.015443 & 0.00464 & 3.33 & 0.0011 \\
Area*Age & -0.004661 & 0.00464 & -1.00 & 0.3166 \\
\hline
\end{tabular}

Interaction: Area*Age

Table 3 Serum PSA levels in 2009, 2010 and their variance rate in the hotspot area

\begin{tabular}{lllll}
\hline Number & Age & \multicolumn{2}{l}{ Serum PSA $(\mathrm{ng} / \mathrm{mL})$} & \multirow{2}{*}{ Variance rate $(\%)$} \\
\cline { 3 - 4 } & & 2009 & 2010 & \\
\hline 1 & 73 & 7.48 & 8.65 & 15.7 \\
2 & 64 & 3.84 & 7.88 & 105.4 \\
3 & 80 & 3.15 & 3.00 & -4.8 \\
4 & 75 & 3.37 & 5.09 & 51.0 \\
5 & 74 & 6.06 & 8.02 & 32.5 \\
6 & 60 & 4.49 & 6.42 & 43.1 \\
\hline
\end{tabular}

Table 4 Comparison of PSA levels in farmers between the hotspot and non-sprayed areas

\begin{tabular}{llll}
\hline Characteristics & $\begin{array}{l}\text { Hotspot area } \\
(n=52)\end{array}$ & $\begin{array}{l}\text { Non-sprayed } \\
\text { area }(n=31)\end{array}$ & $p$ value* \\
\hline Age (mean $\pm \mathrm{SD})($ years $)$ & $69 \pm 5.4$ & $65.1 \pm 5.5$ & 0.002 \\
PSA (GM, GSD) $(\mathrm{ng} / \mathrm{mL})$ & $0.95,2.66$ & $1.00,2.26$ & 0.811 \\
\hline
\end{tabular}

Two people who gave multiple answers were excluded

$S D$ standard deviation, $G M$ geometric mean, $G S D$ geometric standard deviation

* Student's $t$ test (PSA values have been log-transformed)

answered that their families had suffered from prostate cancer.

\section{Discussion}

We found no significant difference between the PSA levels of subjects in the hotspot and non-sprayed areas in our study. The mean age of the subjects in the hotspot area (68.0 years) was significantly higher than those in the nonsprayed area (65.0 years), and it is known that PSA levels can increase naturally with age [13]. In our study on Vietnamese, we found that the prevalence of high PSA levels $(>3 \mathrm{ng} / \mathrm{mL})$ did not differ significantly between the hotspot and non-sprayed areas, although it tended to be higher in the hotspot area (14 of 101 men, $13.9 \%$ ) than in the non-sprayed area ( 9 of 97 men, $9.3 \%$ ). A recent cohort study of United States Vietnam War veterans found a
Table 5 Comparison of PSA levels for other occupations between the hotspot and non-sprayed areas

\begin{tabular}{llll}
\hline Characteristics & $\begin{array}{l}\text { Hotspot area } \\
(n=15)\end{array}$ & $\begin{array}{l}\text { Non-sprayed } \\
\text { area }(n=18)\end{array}$ & $p$ value* \\
\hline Age (mean $\pm \mathrm{SD})($ years) & $64.5 \pm 4.5$ & $66.9 \pm 5.5$ & 0.181 \\
PSA (GM, GSD) (ng/mL) & $0.93,2.07$ & $0.94,2.31$ & 0.986 \\
\hline
\end{tabular}

Two people who gave multiple answers were excluded

$S D$ standard deviation, $G M$ geometric mean, GSD geometric standard deviation

* Student's $t$ test (PSA values have been log-transformed)

Table 6 Comparison of PSA levels between combatants and civilians in non-sprayed area

\begin{tabular}{llll}
\hline Characteristics & $\begin{array}{l}\text { Combatant } \\
(n=71)\end{array}$ & $\begin{array}{l}\text { Civilian } \\
(n=26)\end{array}$ & $p$ value \\
\hline Age (mean $\pm \mathrm{SD})($ years $)$ & $65.8 \pm 4.7$ & $66.9 \pm 6.0$ & $0.118^{1}$ \\
PSA (GM, GSD) $(\mathrm{ng} / \mathrm{mL})$ & $0.98,2.23$ & $0.88,2.19$ & $0.540^{2}$
\end{tabular}

PSA values have been log-transformed

$S D$ standard deviation, $G M$ geometric mean, GSD geometric standard deviation

${ }^{1}$ Welch test, ${ }^{2}$ Student's $t$ test

Table 7 Comparison of PSA levels between exposed and nonexposed subjects in non-sprayed area

\begin{tabular}{llll}
\hline Characteristics & $\begin{array}{l}\text { Exposed } \\
(n=47)\end{array}$ & $\begin{array}{l}\text { Non-exposed } \\
(n=47)\end{array}$ & $p$ value \\
\hline Age (mean $\pm \mathrm{SD} ;$ years) & $66.0 \pm 4.3$ & $66.9 \pm 5.7$ & $0.393^{1}$ \\
PSA (GM, GSD; ng/mL) & $0.93,2.10$ & $0.96,2.25$ & $0.833^{2}$ \\
\hline
\end{tabular}

PSA values have been log-transformed

Three people who answered "unknown" were excluded

$S D$ standard deviation, $G M$ geometric mean, GSD geometric standard deviation

${ }^{1}$ Welch test, ${ }^{2}$ Student's $t$ test

higher incidence of abnormal PSA levels (PSA $>4 \mathrm{ng} / \mathrm{mL}$ ) in the cohort exposed to Agent Orange than in the unexposed cohort [10]. In contrast, The follow-up of six men in 2010 showed that PSA levels increased in all cases except one. A digital rectal examination of these six men detected prostate gland abnormalities in three of them. The United States Food and Drug Administration has approved the PSA test along with a digital rectal exam to help detect prostate cancer in men aged 50 and older [14]. Three of these six men were found to have PSA levels of between 4 and $10 \mathrm{ng} / \mathrm{mL}$ in 2010. According to the American Cancer Society, a PSA level of between 4 and 10 indicates a $25 \%$ chance of prostate cancer; therefore they were advised to have a PSA blood test, a prostate biopsy, or a transrectal ultrasound in hospital. 
Several studies have specifically focused on the possible links between prostate cancer and Agent Orange, including an evaluation of occupational exposure. The association between Agent Orange exposure and prostate cancer has primarily been studied in the setting of the farming and forestry industries [15-18]. Numerous studies have described farming to be a potential occupational exposure that may increase the incidence of prostate cancer and therefore increase PSA levels [13]. We compared PSA levels with occupational categories (farmer and others) but found no significant differences in PSA levels between the hotspot and non-sprayed areas.

A total of 47 subjects in the control group reported exposure to Agent Orange during the Vietnam War, with a further 47 reporting no exposure. However, there was no significant difference between these two sub-groups in terms of PSA levels. Moreover, 71 were combatants and 26 were civilians during the Vietnam War. We compared the PSA levels of these two groups as combatants were more likely to have been exposed during the Vietnam War, but found no significant differences. Other studies have also found no statistically significant difference between Vietnam veterans exposed or not to Agent Orange in terms of PSA levels [10, 19].

Although this is first study of the relationship between Agent Orange and PSA in Vietnam, it has several limitations. The first such limitation concerns the small number of subjects. The second limitation is that the mean age of the subjects differed significantly between the hotspot and nonsprayed areas and it is known that PSA levels can increase naturally with age [13]. An additional limitation of our study is that we did not quantify the levels of dioxin, therefore future studies should include a higher number of subjects from the two areas and quantify the levels of dioxin in serum. Consequently, the present study found the following:

1. This is first study concerning the relationship between Agent Orange and PSA in Vietnam.

2. The PSA levels were similar between the hotspot area and the non-sprayed area, although the prevalence of high PSA levels tended to be higher in the former than in the latter.

3. Some subjects from the hotspot area who showed high PSA levels in 2009 had similarly high levels in 2010, thus suggesting the possibility of prostate cancer.

Acknowledgments This study was supported by the grants from the Japan Society for the promotion of science (Grant-in-Aid for Scientific Research, (B) No. 23406018 and Grant-in-Aid Scientific Research (A) No. 19209021). We would like to thank all the participants in Phu Cat and Kim Bang.
Conflict of interest The authors declare that they have no conflict of interest regarding the publication of this article.

\section{References}

1. CRS Report for Congress. Veterans affairs: health care and benefits for veterans exposed to Agent Orange. 2008.

2. U.S. Vietnam Veterans and Agent Orange. National Organization on Disability with funding from the Ford Foundation Special Initiative on Agent Orange/Dioxin. 2009. http://www.fordfound.

3. Institute of medicine. Veterans and Agent Orange: health effects of herbicides used in Vietnam. Washington, DC: National Academy Press; 1994.

4. Institute of medicine. Veterans and Agent Orange: update 1998. Washington, DC: National Academy Press; 1999.

5. Ketchum NS, Michalek JE, Burton E. Serum dioxin and cancer in veterans of Operation Ranch Hand. Am J Epidemiol. 1999;143:630-9.

6. Akhtar FZ, Garabrant HD, Ketchum NS, Michalek JE. Cancer in US Air Force veterans of the Vietnam War. J Occup Environ Med. 2004;46:123-36.

7. Giri VN, Cassidy AE, Beebe-Dimmer J, Ellis LR, Smith DC, Bock $\mathrm{CH}$, et al. Association between Agent Orange and prostate cancer: a pilot case-control study. Urology. 2004;63:757-60.

8. Pavuk M, Michalek JE, Ketchum NS. Prostate cancer in US Air Force veterans of the Vietnam War. J Expo Sci Environ Epidemiol. 2006;16:184-90.

9. Justine L, Gina A, Lin F. Vietnam military service and history and prostate cancer. Biol Med Central Public Health. 2006. http://www.biomedcentral.com/1471-2458/6/75.

10. Chamie K, de Vere White RW, Lee D, Ok JH, Ellison LM. Agent Orange exposure, Vietnam War veterans and the risk of prostate cancer. Cancer. 2008;113:2464-70.

11. Brosman SA. Prostate-specific antigen: updated: Apr 27, 2009. http://emedicine.medscape.com.

12. Nhu DD, Kido T, Naganuma R, Suzuki H, Kuroda N, Honma S, et al. Salivary cortisol and cortisone levels, and breast milk dioxin concentrations in Vietnamese primiparas. Toxicol Environ Chem. 2010;92:1939-52.

13. Keetch DW, Catalna WJ, Smith DS. Serial prostatic biopsies in men with persistently elevated serum prostate specific antigen values. J Urol. 1994;151:1571-4.

14. National Institutes of Health. U.S. Department of Health, and Human Services; 2009.

15. Manz A, Berger J, Dwyer JH, Flesch-Janys D, Nagel S, Waltsgott H. Cancer mortality among workers in chemical plant contaminated with dioxin. Lancet. 1991;338:959-64.

16. Morrison H, Savitz D, Semenciw R, Hulka B, Mao Y, Morison D, et al. Farming and prostate cancer mortality. Am Epidemiol. 1993;137:270-80.

17. Becher H, Flesch-Janys D, Kauppinen T, Koqevinasm M, Sreindorf K, Manza A, et al. Cancer mortality in German male workers exposed to phenoxy herbicides and dioxins. Cancer Causes Control. 1996;7:312-21.

18. Keller-Byrne JE, Khuder SA, Schaub EA. Meta-analysis of prostate cancer and farming. Am J Ind Med. 1997;31:580-6.

19. Zafar MB, Terris MK. Prostate cancer detection in veterans with a history of Agent Orange exposure. J Urol. 2001;166:100-3. 